\title{
PRESENÇA DA BIBLIOMETRIA COMO PROCESSO METODOLÓGICO EM TESES INDEXADAS NO IBICT (2005-2015)
}

\author{
André Philippe Villanova \\ Mestrando do PPGCTS - UFSCAR \\ andre.villanova@usp.br \\ Marcia Regina da Silva \\ Docente do Departamento de Educação, Comunicação e Informação e do PPGCTS -/UFSCar \\ Doutora em Educação \\ marciaregina@usp.br
}

Resumo

\begin{abstract}
Este trabalho tem como objetivo investigar e analisar a produção acadêmica brasileira, representada pelas teses indexadas na Biblioteca Digital Brasileira de Teses e Dissertações do Instituto Brasileiro de Informação em Ciência e Tecnologia (BDTD/IBICT), que utilizaram a Bibliometria como referencial metodológico. Na esfera teórica esta pesquisa se alicerça nos estudos sobre a comunicação científica, mais especificamente nos constructos da Bibliometria. Do ponto de vista metodológico, caracteriza-se por ser uma pesquisa exploratória na qual o BDTD/ IBICT foi utilizado para a construção de indicadores bibliométricos. As análises tiveram como direcionamento os procedimentos intrínsecos da ciência (caixa-preta), representada pelas metodologias. Os resultados obtidos revelam que os estudos bibliométricos estão em expansão e, geralmente, são empregados em associação com outras metodologias. O fomento para estas pesquisas cresce de maneira menos acentuada do que a produção. As pesquisas bibliométricas são, em grande parte, exploratórias, descritivas, quanti-qualitativas e documentais, as fontes de coleta variam e se relacionam, mas as bases de dados são as mais requeridas. Percebeu-se que alguns programas de pós-graduação tendem a utilizar determinadas metodologias, sugerindo polos específicos de estudos. As metodologias utilizadas concomitantemente com a Bibliometria são diversas, a mais recorrente é a análise de conteúdo. Conclui-se que a utilização de metodologias concomitantes com a Bibliometria está sendo mais explorada.
\end{abstract}

Palavras-chave: Análise Bibliométrica. Bibliometria. Indicadores. Metodologias.

\section{INTRODUÇÃO}

A necessidade de avaliar a produção do conhecimento, mais especificamente o conhecimento institucionalizado, é de suma importância para o desenvolvimento da sociedade. Existem diversos caminhos para obter tal avaliação, uma forma viável e muito utilizada é ter como objeto de estudos a produção bibliográfica, já que a mesma fornece indícios importantes que permitem traçar um panorama dos rumos da ciência. Análises dessa natureza geralmente se baseiam em metodologias quantitativas, que tanto podem levantar aspectos relevantes da produção como podem servir como embasamento para pesquisas básicas e aplicadas.
A Bibliometria é uma abordagem metodológica quantitativa utilizada com este propósito, trata-se de uma disciplina alicerçada em modelos teóricos e aplicados que tem como objeto de estudos a Bibliografia. A Bibliometria tem suas raízes na Ciência da Informação e constitui-se em uma disciplina estabelecida para a análise e avaliação da produção científica. Além disso, tem um papel importante para avaliação de insumos e produtos, bem como para avaliação de aspectos intrínsecos da atividade científica. Justamente por essa razão, tem importância para as nações que dão ênfase em sua produção cientifica, como produto científico e mecanismo de desenvolvimento. 
A análise bibliométrica baseia-se na construção de indicadores a partir de documentos publicados (KOBASHI, 2006). Os indicadores são definidos como a quantificação dos aspectos intangíveis baseados em descritores das pesquisas e, geralmente, são divididos em indicadores de produção, indicadores de citação e indicadores de ligação. Os indicadores de produção abrangem os insumos e produtos e qualquer outro relacionado com a produção científica e prepondera a analise linear da razão, diretamente proporcional entre os investimentos (insumos) e os resultados (produtos). Já os indicadores de citação são geralmente associados com a qualidade dos produtos, porém esta visão é amplamente discutida e criticada. Os indicadores de ligação, por sua vez, oferecem geralmente um mapa de ligações, sendo eles individuais, de instituições, entre outros, que nos oferece uma ampla gama de análise (FARIA, 2001).

A Bibliometria teve seu caráter aprofundado e expandido. Indicadores como a produção dos autores e a dispersão do conhecimento, foram surgindo à medida do tempo, sempre com o delineamento de aperfeiçoar a avaliação científica, tanto de um modo especializado, como de um modo mais abrangente. Com isso, outras áreas da avaliação científica começaram a ganhar corpo próprio a partir da Bibliometria, tais como a Cientometria, Patentometria, Webometria e a Infometria.

Mesmo havendo divergências sobre a abrangência dessas áreas, suas bases vêm da Bibliometria, conforme Maricato e Noronha (2013, p.62) reiteram:

[...] entende-se que o conjunto de métodos e técnicas abrangidas pelos estudos métricos da informação, a Bibliometria tem caráter central e integrador, podendo ser considerada a "disciplina mãe", correlacionando-se de um modo interdisciplinar com as demais, que, por sua vez, possuem suas particularidades e aplicações próprias.

Além de sua expansão epistemológica, novas perspectivas sobre indicadores surgiram. Os indicadores são tradicionalmente denominados de duas formas: os de Input, ou insumos, e os de Output, ou resultados e produtos, porém indicadores que advém da atividade científica (caixa preta) vem ganhando notoriedade. Segundo Spinak (1998), os indicadores de input, são de menor complexidade, pois estão mais atrelados a administração e muito superficiais para a avaliação da ciência, então as pesquisas foram se direcionando cada vez mais para os indicadores de output.

Entretanto, Maricato e Noronha (2013) propõem a utilização de um modelo sistêmico formado por "Input - Atividade Científica Tecnológica (caixa preta) - Output". Diante do avanço das pesquisas com um viés sistêmico, as pesquisas começaram a investigar a "Caixa Preta" na qual novos indicadores estão surgindo, favorecendo a avaliação.

Embora seja uma área consolidada, a Bibliometria como modelo pesquisa quantitativo, não está isenta de críticas. Conforme aponta Pierre Bourdieu (2004, p.28),

[...] dever-se-ia, em especial, examinar os limites de um método que se apoia em critérios estritamente quantitativos e que ignoram as modalidades e as funções muito diversas da referência (podendo ir ao ponto de colocar entre parênteses a diferença entre as citações positivas e as citações negativas). Apesar das utilizações duvidosas (e por vezes deploráveis) da bibliometria, estes métodos podem servir para construir indicadores úteis no plano sociológico, como fiz em Homo Academicus.

O grande desconforto dos estudos métricos é representar numericamente um determino escopo científico. O caráter avaliativo da Bibliometria gera questionamentos, principalmente no que se refere aos procedimentos de pesquisa utilizados para a construção de indicadores. Para reforçar as práticas de pesquisas com esse direcionamento, foi criado em 2014, publicado em 2015, o manifesto Leiden, que visa demonstrar práticas para que os avaliadores possam confiar em seus trabalhos (Quadro 1). 
Quadro 1. Os dez princípios do manifesto Leiden

1. A avaliação quantitativa deve dar suporte à avaliação qualitativa especializada.

2. Medir o desempenho de acordo com a missão da instituição, do grupo ou do pesquisador.

3. Proteger a excelência da pesquisa localmente relevante.

4. Manter a coleta de dados e os processos analíticos abertos, transparentes e simples.

5. Permitir que os avaliados verifiquem os dados e as análises.

6. Considerar as diferenças entre áreas nas práticas de publicação e citação.

7. Basear a avaliação de pesquisadores individuais no juízo qualitativo da sua carreira.

8. Evite solidez mal colocada e falsa precisão.

9. Reconhecer os efeitos sistêmicos da avaliação e dos indicadores.

10. Examinar e atualizar os indicadores regularmente.

\section{Fonte: (HICKS et al., 2015)}

Iniciativas como esta estabelecem práticas de conduta, uma forma associativa de protocolo para estudos métricos da informação, o que fortalece o estudo métrico da ciência e dão suporte para o desenvolvimento e credibilidade para mais estudos, esses fatores ligados a interdisciplinaridade e a associação com outras metodologias (Escopo desta pesquisa), colocam os estudos métricos na ciência, em uma posição privilegiada na vanguarda da academia.

Sendo assim, entende que o estudo desta temática pode contribuir para o desenvolvimento de competências para a elaboração de indicadores bibliométricos que, como já referido anteriormente, fortalece o desenvolvimento da ciência por meio do diagnóstico e projeções sobre temas, áreas, disciplinas, grupos, etc. Tendo como parâmetro que a produção acadêmica representa os caminhos de formação dos pesquisadores, atribui-se a esses documentos valor singular para a caracterização de uma área. Dessa forma, levantam-se as seguintes questões:

Onde se concentram os trabalhos com referencial metodológicos da Bibliometria? Em quais áreas? Existe fomento para tais pesquisas? Quem são os orientadores destes trabalhos? Quais as ferramentas bibliométricas que estas pesquisas utilizam? Quais metodologias estão sendo empregadas concomitantemente com a Bibliometria?

Para responder as questões apresentadas, o objetivo geral desta pesquisa é investigar e analisar a produção acadêmica brasileira, representada pelas teses indexadas na Biblioteca Digital Brasileira de Teses e Dissertações do Instituto Brasileiro de
Informação em Ciência e Tecnologia (BDTD/IBICT), que utilizaram a Bibliometria como referencial metodológico; Tem-se como intuito mapear a inserção da Bibliometria no contexto da formação científica brasileira, e relações decorrentes descritas em perguntas no parágrafo anterior.

A justificativa desta pesquisa é que a Bibliometria tem sido empregada com outras metodologias de pesquisa para endossar e aprimorar indicadores quantitativos construídos por meio de análises bibliométricas, outro fator é sobre a utilização de indicadores do processo científico (caixa preta), que são pouco utilizados na análise bibliométrica se compararmos a indicadores de input (entrada, insumos), ou de output (saída, produtos). Por isso, a construção desta pesquisa será importante para contribuir com o campo no sentido de trazer indícios que possam embasar pesquisas futuras. Além desta introdução, este artigo abordará os aspectos metodológicos da pesquisa, apresentará os resultados $\mathrm{e}$ as considerações finais $\mathrm{da}$ pesquisa.

\section{CAMINHOS METODOLÓGICOS}

Esta pesquisa é exploratória e descritiva, com abordagem quanti-qualitativa e do tipo bibliográfica. Os procedimentos metodológicos seguiram as fases: levantamento das teses na BDTD/IBICT; coleta de dados; organização dos dados; análise bibliométrica; construção de indicadores e análise dos resultados.

Alguns critérios foram adotados para a acuidade do levantamento das teses na BDTD/IBICT, descritos no Quadro 2. 
Quadro 2 -Critérios para segurança dos dados

- os descritores e estratégias de busca foram definidos após pesquisa bibliográfica;

- para garantir a integridade das informações coletadas foi realizado o download das teses e o salvamento de cópias de segurança;

- para garantir a validade dos resultados obtidos a busca e os downloads foram realizados em um curto período para evitar que atualizações constantes do banco de dados pudessem modificar o total de registros recuperados.

\section{Fonte: Elaborado pelos Autores}

Levando em consideração os aspectos indicados, restringiu-se a busca pela modalidade "Teses" na BDTD/IBICT. A escolha deste trabalho acadêmico deveu-se pela maturidade dos trabalhos. Utilizou-se como limitadores de busca o período entre os anos de 2005 a 2015 e a expressão "Bibliometr* OR cientometr* OR cienciometr*" em todos campos. Esta estratégia de busca resultou em 106 registros.

Nem todas as teses recuperadas foram utilizadas na pesquisa, para os critérios de validação foram elaboradas duas etapas de intervenção: a primeira foi no momento da coleta, os documentos descartados foram aqueles em que não foi possível o acesso aos documentos ou a recuperação nos remeteu a trabalhos repetidos. A segunda etapa deu-se após o contato com os materiais e na organização dos dados, momento que se percebeu que alguns trabalhos não se enquadravam nos objetivos da pesquisa, como trabalhos que não utilizam a Bibliometria e trabalhos que são uma compilação de artigos, os quais inviabilizaria a utilização destes, pois cada artigo dentro da compilação geraria seus próprios descritores. Após este percurso, a quantidade de teses utilizadas na pesquisa foi de 77 (setenta e sete).

Os descritores utilizados nesta pesquisa foram: Orientador, Ano, Instituição,
Programa, Fomento, Palavras-chave, Fonte de Coletas, Ferramentas Utilizadas, Tipo de Pesquisa, Outras Metodologias. Os descritores: Número de controle, Autor e título foram recuperados para uma organização operacional, são importantes para o controle bibliográfico, mas não foram utilizados na elaboração dos indicadores.

\section{INDICADORES BIBLIOMÉTRICOS DAS TESES INDEXADAS NO IBICT}

A elaboração de indicadores envolve responsabilidade do pesquisador, como discutido na comunidade e apresentado no Manifesto Leiden. A análise dos dados dos indicadores representa a verdadeira contribuição da pesquisa, pois ao utilizarem-se os conceitos da gestão da informação, no qual a informação são dados contextualizados e conhecimento são informações institucionalizadas, a proposta de uma análise contextualiza se torna inerente a Bibliometria, nessa visão, "os estudos bibliométricos realizam uma leitura de dados bibliométricos à luz de elementos do contexto sócio histórico em que a atividade científica é produzida" (ARAÚJO, 2006. p.25).

Com este pressuposto, os indicadores cronológicos serão os primeiros a serem discutidos.

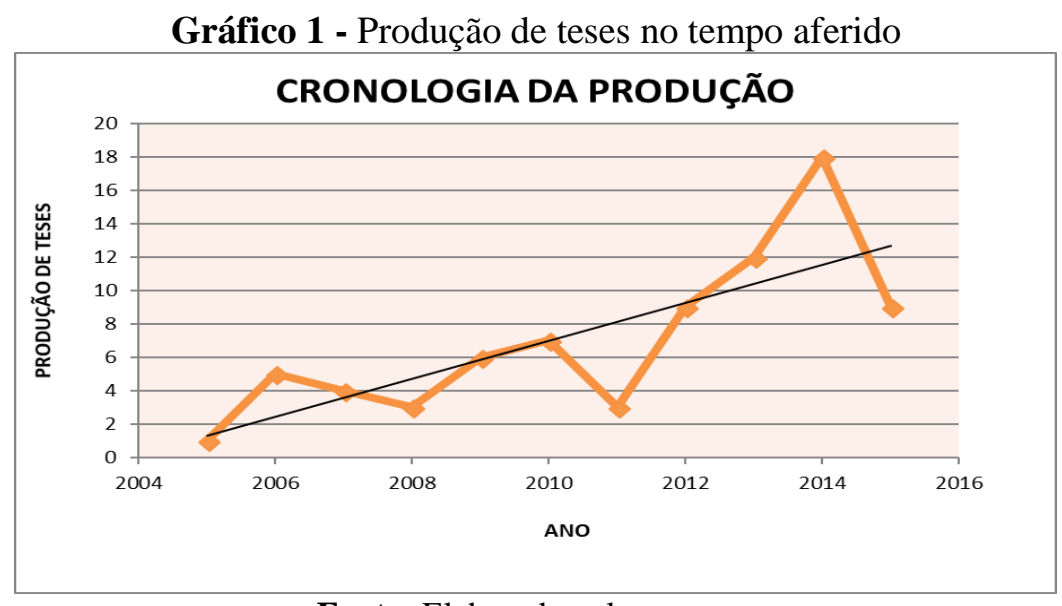

Fonte: Elaborado pelos autores 
Apesar do crescimento observado no Gráfico 1, mesmo oscilante, o número teses é relativamente baixo em relação ao total das teses disponibilizadas na BDTD/IBICT, devido às características de interdisciplinaridade da Bibliometria. Iniciativas como o Encontro Brasileiro de Bibliometria e Cientometria (EBBC), iniciado em 2008, no Rio de Janeiro, podem ter contribuído para mudar este quadro, pois as teses iniciadas em 2009 foram concluídas em 2012, ano em que se iniciou um crescente do tema para um patamar superior em relação aos anos anteriores, mesmo com a queda em 2015.

Continuando a investigação, depois deste indicador de output, o indicador de fomento recebido, indicador de input, poderá demonstrar indícios relevantes

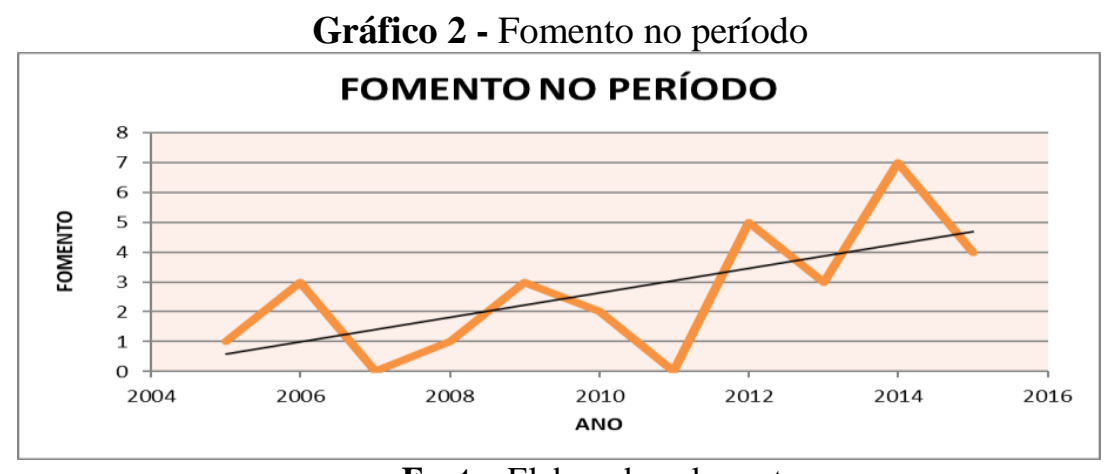

Fonte: Elaborado pelos autores

O fomento também oscila, não de forma idêntica a produção, o que impede de fazer uma associação direta entre os indicadores, mas analisando-se as linhas de tendência de ambos os Gráficos 1 e 2, nota-se que há crescimento, com uma angulação um pouco maior na produção, significando que produção tende a crescer numa proporção maior do que $\mathrm{o}$ fomento. A relação linear e direta e equivalente não ocorre, mas existe uma relação forte.

Para elucidar mais este fenômeno da produção das teses, buscou-se outro indicador de produção com a finalidade relacional, tratase dos Programas de Pós-Graduação mais produtivos no que se refere a frequência de Teses como a temática Bibliometria.

Gráfico 3 - Cronologia dos programas de pós-graduação mais produtivos

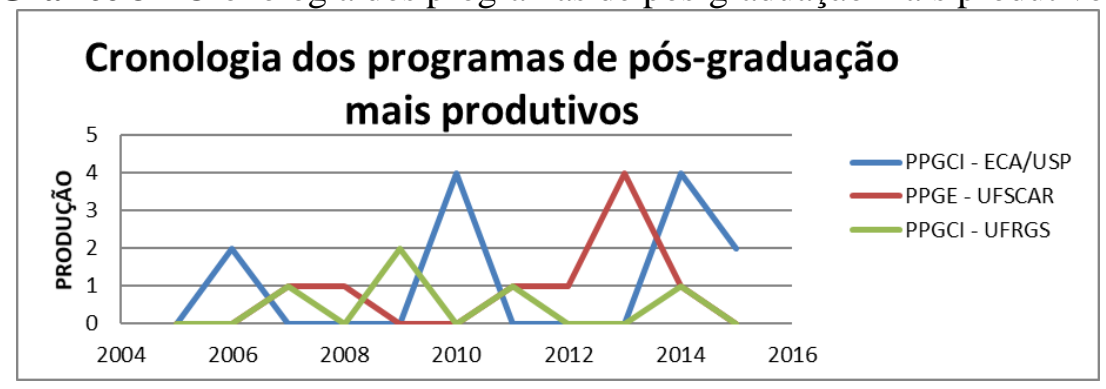

Fonte: Elaborado pelos autores

O Gráfico 3 demonstra que o PPGCI teve no período analisado três grandes picos de produção sobre a temática a cada quatro anos, o PPGE da UFSCar teve um pico em 2013, logo após sediar o EBBC e o PPGCI da UFRGS teve uma produção menor, porém mais constante.

$\mathrm{O}$ indicador de produção dos orientadores aprofundará a perspectiva das instituições e seus agentes, a visualização das informações neste indicador destacará os orientadores que orientaram mais de uma tese, pois há uma gama grande de orientadores que estão presentes em apenas um registro, fato considerado como eventual, o que desviaria da análise de uma busca de padrões e tendências. 


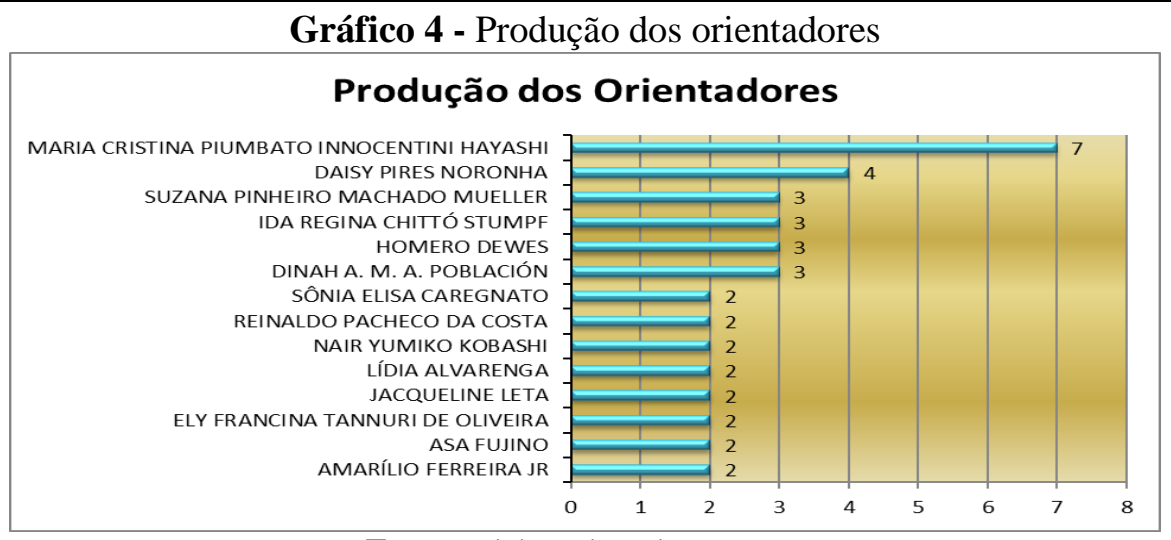

Fonte: Elaborado pelos autores

A orientadora Maria Cristina Piumbato Innocentini Hayashi orientou o maior número de trabalhos sobre Bibliometria, sua participação tão relevante pode ter um vínculo com o fato de lecionar em dois programas de pós-graduação aferidos na pesquisa (PPGE UFSCAR e PPGEE - UFSCAR).

Em relação ao fomento, é certo afirmar que apenas o fomento por si só não é responsável pelo desenvolvimento ou atrofiamento de uma área acadêmica, mas o fomento é uma forma consagrada de estímulo e com resultados amplamente discutidos e reconhecidos para o desenvolvimento. Conhecer a quantidade e quais instituições de fomento que estão atuando na área amplia a visão do objeto.

Gráfico 5 - Instituições de fomento

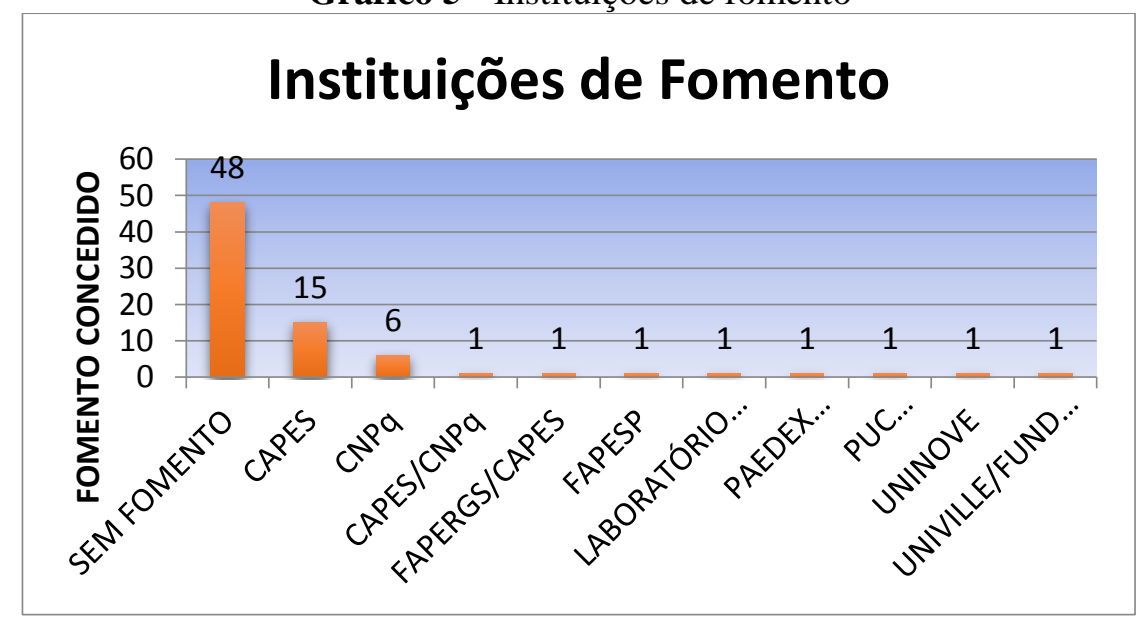

Fonte: Elaborado pelos autores

\subsection{INDICADORES DA "CAIXA PRETA"}

Utiliza-se o termo "caixa preta" para este conjunto de indicadores porque são eventos, processos e procedimentos que ocorrem dentro do trabalho acadêmico, em outras palavras, não são aferidos como insumos, e nem como produtos, segundo Latour $(2011$, p.4) “'...] por mais controvertida que seja sua história, por mais complexo que seja seu funcionamento interno, por maior que seja a rede comercial ou acadêmica para sua implementação, a única coisa que conta é o que se põe nela e o que dela se tira". No caso desta pesquisa, investigaremos o tipo de pesquisa utilizado nas Teses. 


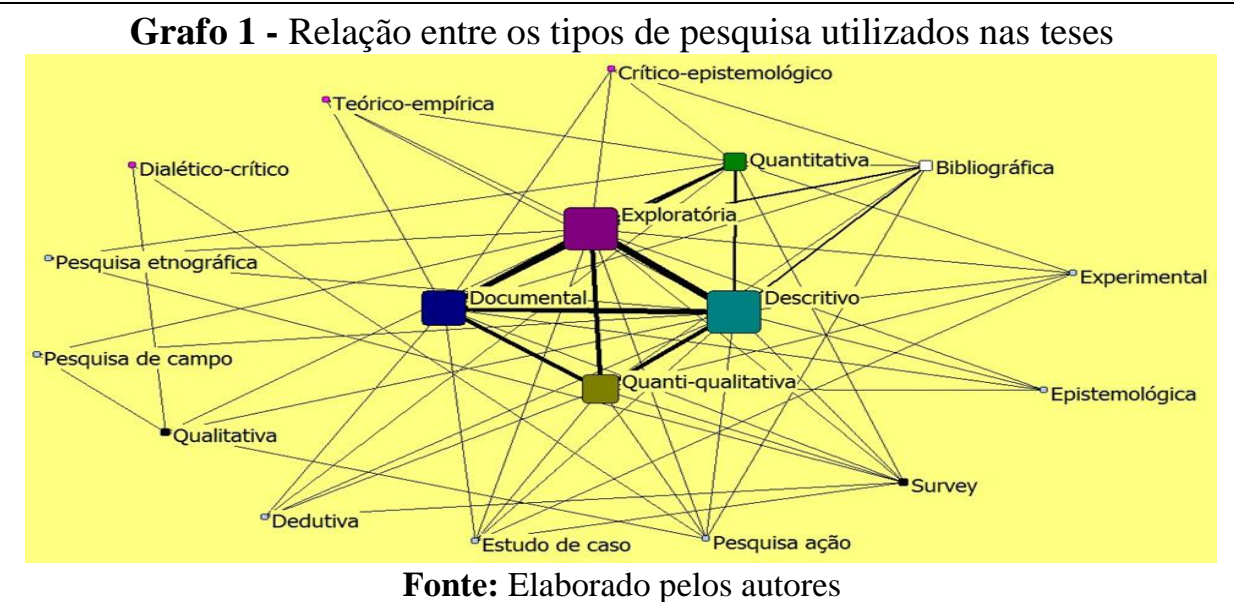

Pelo Grafo 1, percebe-se de forma contundente que a abordagem bibliométrica é predominantemente declarada como Exploratória, Descritiva, Quanti-qualitativa e Documental com pequenas variantes. Percebese o aparecimento de diversos tipos de pesquisas que são utilizadas concomitantemente com a Bibliometria.

A contextualização será aprimorada analisando as fontes de coleta dos dados dos trabalhos, verificando onde a busca de informações se relaciona com o objeto das pesquisas.

No Grafo 2 destacam-se as bases de dados como as fontes de coleta de dados mais recorrentes nas pesquisas. As bases de dados estão cada vez mais aprimorando a qualidade da indexação e de análise dos dados, além de permitirem um refinamento apurado para a coleta de dados. Soma-se ainda a abrangência das temáticas em bases de dados multidisciplinares, tornando-se um recurso informacional importante para a avaliação científica.

A utilização dos bancos de teses e dissertações nos trabalhos bibliométricos também foi significativa. A utilização de banco de currículos também foi observada, tal achado indica uma busca de indicadores individualizados, ou a busca de relação entres os pares. Como existe a possibilidade da utilização de diversas fontes de coleta em um mesmo trabalho, a relação entre eles amplia-se a compreensão, as bases de dados possuem relacionamento com todas as fontes, sugerindo que as bases são a gênese da coleta dos dados, e assim se aprofundando para outras fontes de acordo com o desenvolvimento dos trabalhos.

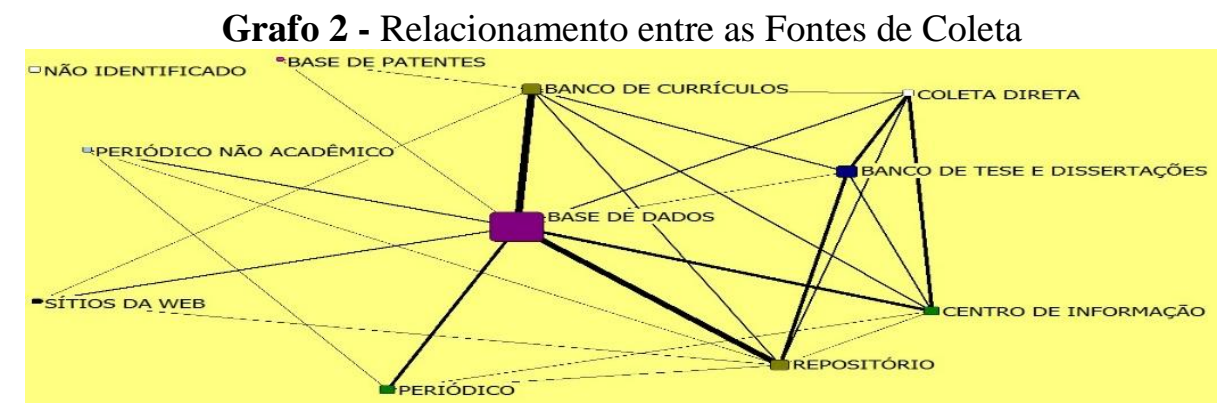

Fonte: Elaborado pelos autores

A continuidade da contextualização das metodologias aplicadas nos trabalhos segue para as ferramentas utilizadas. Para a análise das ocorrências das ferramentas, nota-se que a ocorrência de apenas uma é preponderante, este fato já é relevante, pois indica a grande variabilidade nas opções de ferramentas disponíveis, os nódulos em cor rosa significam apenas uma ocorrência e percebe-se que estas estão utilizadas na maior parte em relação com ao "núcleo duro" (ferramentas com mais de uma ocorrência), há também dois grupos isolados de ferramentas utilizadas em apenas um trabalho cada, indicando possível utilização esporádica. 


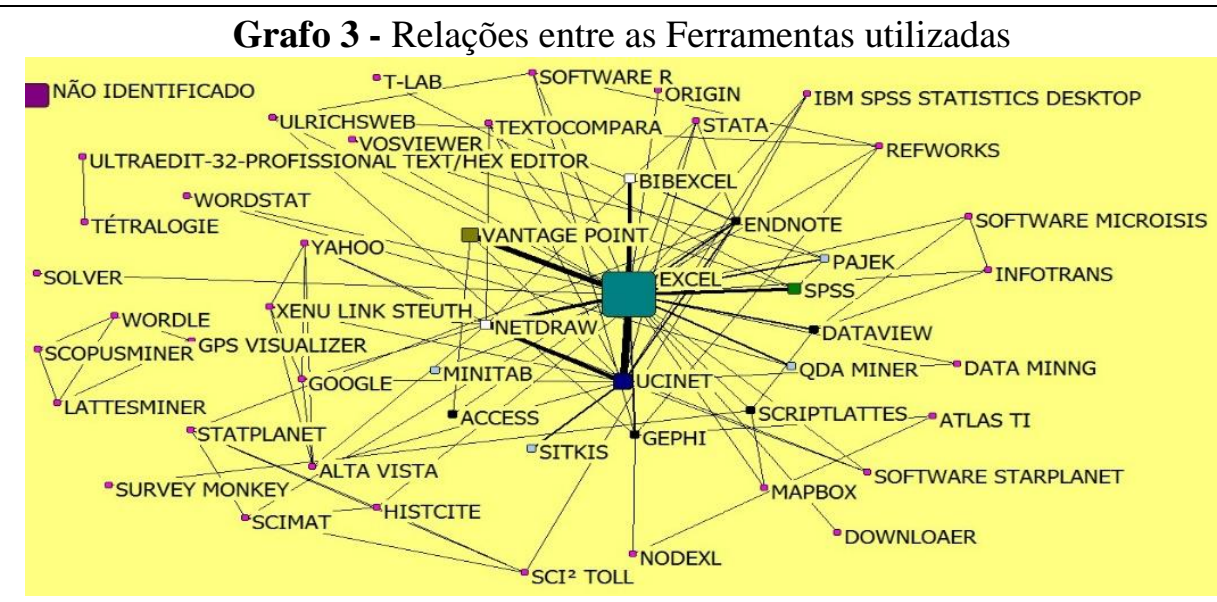

Fonte: Elaborado pelos autores

No "núcleo duro" das ferramentas, o Excel possui destaque e pode ser compreendido pela grande disseminação desta ferramenta e por possuir recursos tanto para organização de dados, como de apresentação da informação.

As palavras-chave são indicadores relevante pois são atribuídas pelo próprio autor. Convencionou-se no Grafo 4 a apresentação das palavras-chave acima de uma ocorrência, isso porque havia um grande número de informações, algumas indicando fatos específicos e ou exclusivos dos trabalhos.

Grafo 4 - Palavras-chave acima de uma ocorrência

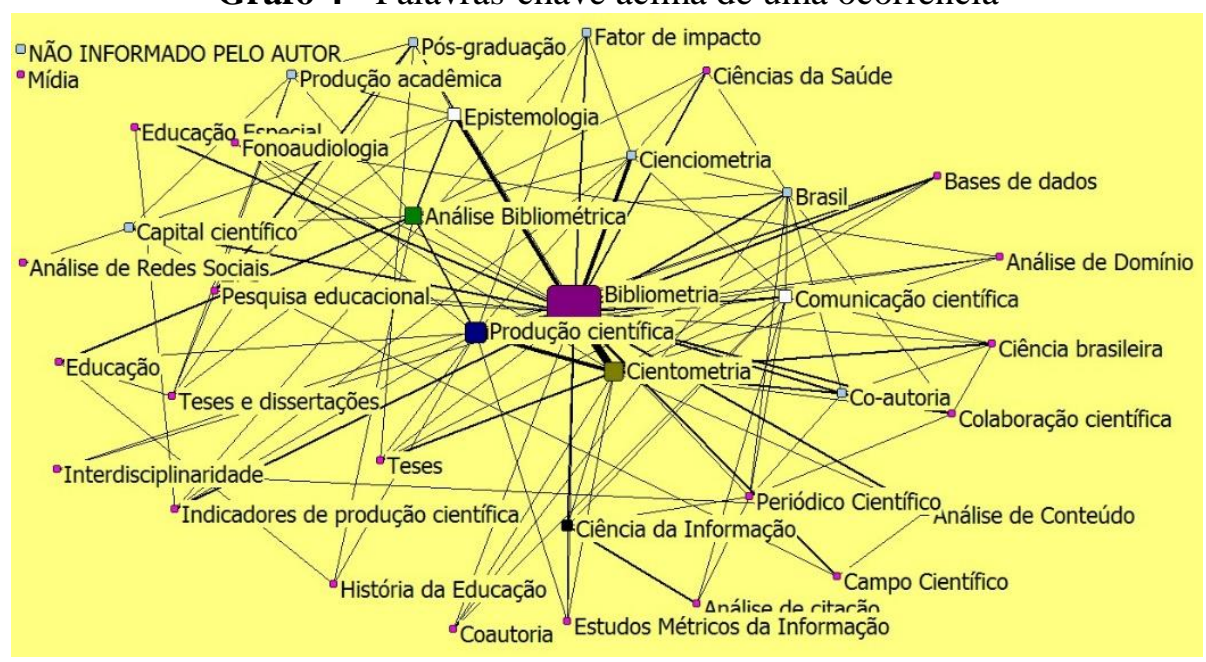

Fonte: Elaborado pelos autores

A palavra-chave mais utilizada é a Bibliometria, seguido das palavras Produção Científica, Cientometria e Análise Bibliométrica, esperava-se este retorno devido a chave de busca utilizada na BDTD/IBICT. Estas palavras possuem relação com a análise do campo acadêmico, sugerindo que a Bibliometria utilizada em produção de teses possui um vínculo forte com análise do campo científico e explorando pouco outras facetas da Bibliometria.

A maior parte das palavras-chave reincidentes se concentra em palavras de estudos métricos da informação, a área científica como um todo e ligados a pósgraduação. Algumas destoam como as ligadas às palavras Educação, Ciências da Saúde e Fisioterapia. Em relação à palavra "Educação" o vínculo poder ser analisado pelo fato da presença de cinco programas de pós-graduação serem voltados para a Educação, como o PPGE - UFSCAR, por exemplo, que foi um Programa bem produtivo no período, fato semelhante ocorre com a palavra "Ciências da Saúde" em menor proporção.

Quanto as metodologias empregadas em conjunto com a Bibliometria, verifica-se no Grafo 5 que são diversas, apenas seis 
metodologias, com exceção da Bibliometria, possuem mais de um registro. A convergência da análise deu-se a partir destas seis metodologias identificadas, mas a visão geral dos relacionamentos é útil antes da convergência.

Grafo 5 - Relacionamento entre Metodologias

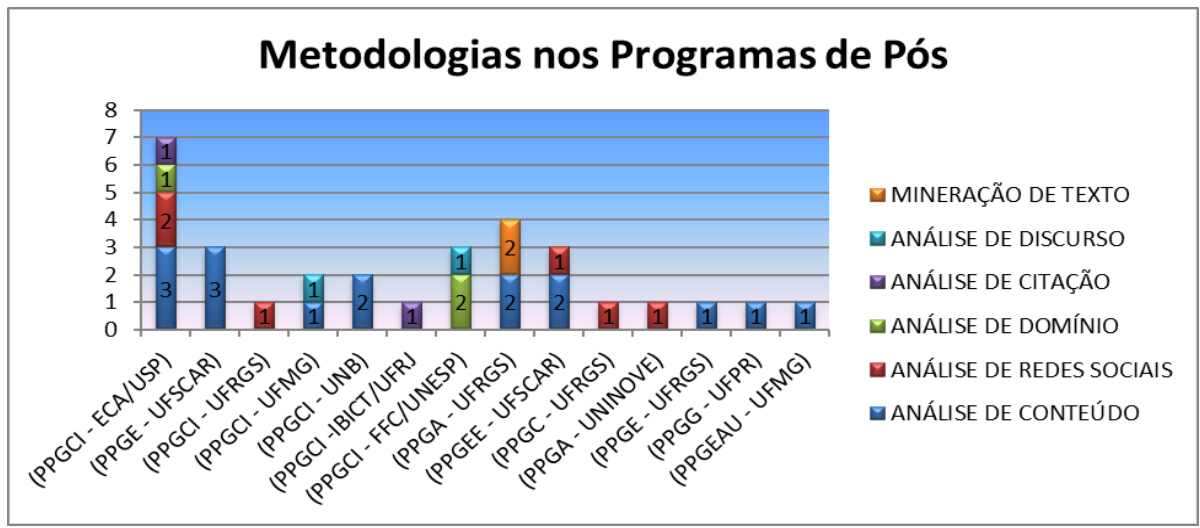

Fonte: Elaborado pelos Autores

Percebe-se no Grafo 5, que as principais associações com a Bibliometria ocorrem com as metodologias de análises, corroborando com a característica de uma pesquisa Quantiqualitativa, como destacado no Grafo 1. Dentro das análises, a Análise de Conteúdo possui maior destaque. 39 trabalhos empregaram outras metodologias associadas a
Bibliometria é 39, um pouco superior a metade dos 77 trabalhos analisados.

No Gráfico 6 são apresentadas as principais metodologias utilizadas nas Teses no período analisado. Neste gráfico são apresentadas as metodologias utilizadas mais de uma vez. Ressalta-se que foi excluído a Bibliometria, pois a mesma está representada em todos os trabalhos.

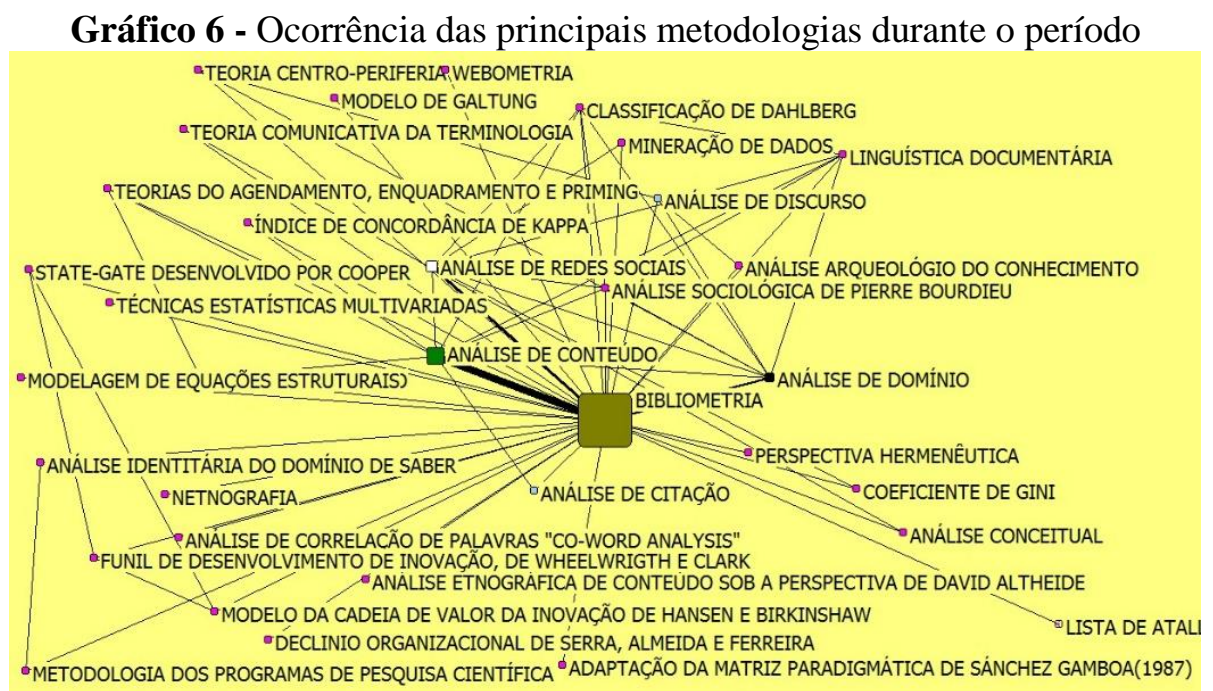

Fonte: Elaborado pelos autores

Nota-se que as principais metodologias utilizadas estão concentradas a partir do ano de 2012, pode-se considerar que houve uma relativa mudança de paradigma. A
Bibliometria antes identificada como puramente "quantitativa", passa a ser associada de forma crescente com outras metodologias. 
Gráfico 7 - Metodologias nos programas de Pós

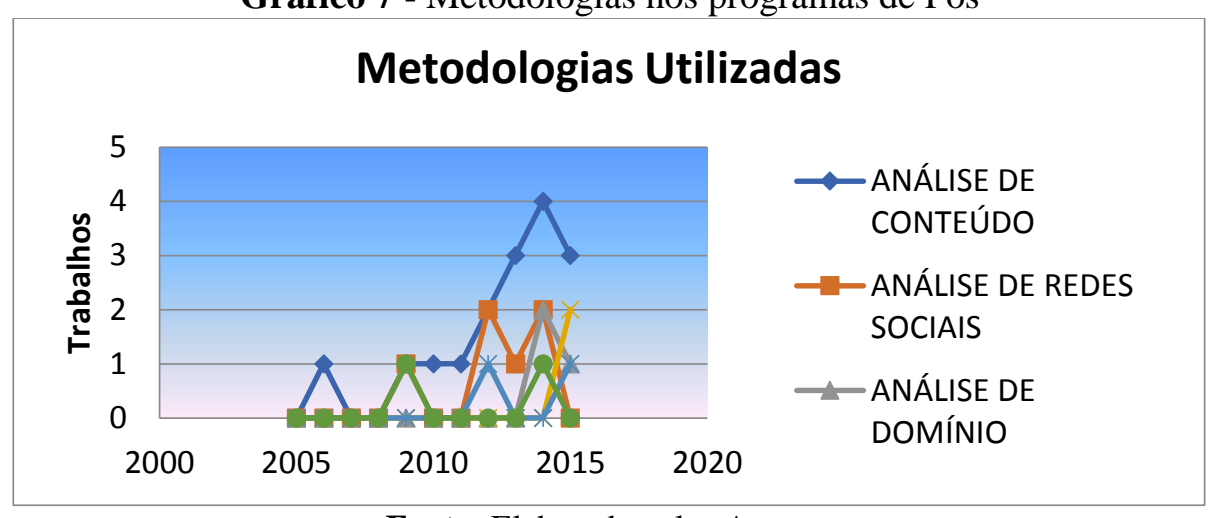

Fonte: Elaborado pelos Autores

Observa-se no Gráfico 7 que a maior diversidade de metodologias ocorre no PPGCI - ECA/USP, fato que se esperava já que este Programa se destacou, no período, como maior produtor de teses na área. Uma informação relevante é que os programas como PPGE UFSCAR e PPGCI UNB, que figuram como produtores expressivos, apresentam apenas a Análise de Conteúdo como metodologia associada. O PPGCI - FFC/UNESP possui três ocorrências em três associações a outras metodologias, e apesar de poucas teses aferidas, é o Programa que mais utilizou a Análise de Conteúdo nos trabalhos bibliométricos. O PPGA - UFRGS apresentou exclusividade na utilização da Mineração de Texto. A ocorrência única nos programas é na maioria da Análise de Conteúdo e Análise de Redes Sociais.

Outro indicador analisado serão as metodologias mais recorrentes e os orientadores mais produtivos. As informações do Gráfico 8, mostram que dos seis orientadores mais produtivos, dois não utilizaram nenhuma das seis metodologias mais utilizadas e, entre as metodologias, há um predomínio da Análise de Conteúdo, porém metade das metodologias não foram empregadas. Conclui-se que os orientadores mais produtivos não são responsáveis direto pela associação de outras metodologias com a Bibliometria, e nem pela diversidade destas metodologias.

Gráfico 8 - Metodologias utilizadas pelos Orientadores

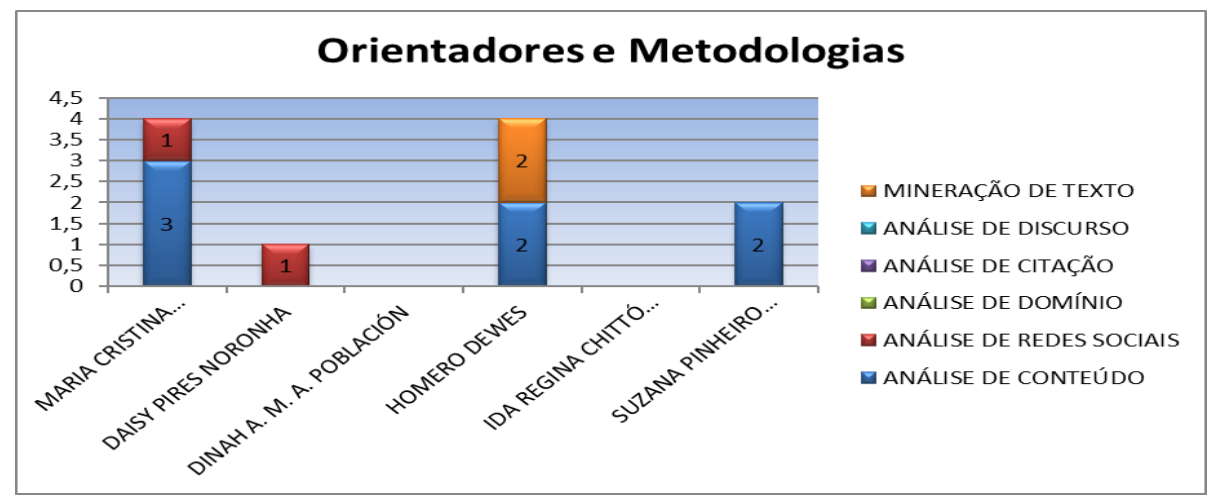

Fonte: Elaborado pelos autores

Nas ocorrências das palavras-chave verificou-se a presença das seis metodologias mais utilizadas nos trabalhos, à importância deste indicador é verificar se metodologias utilizadas são determinantes nas Teses para os autores darem ênfase e escolhessem como palavra-chave. 


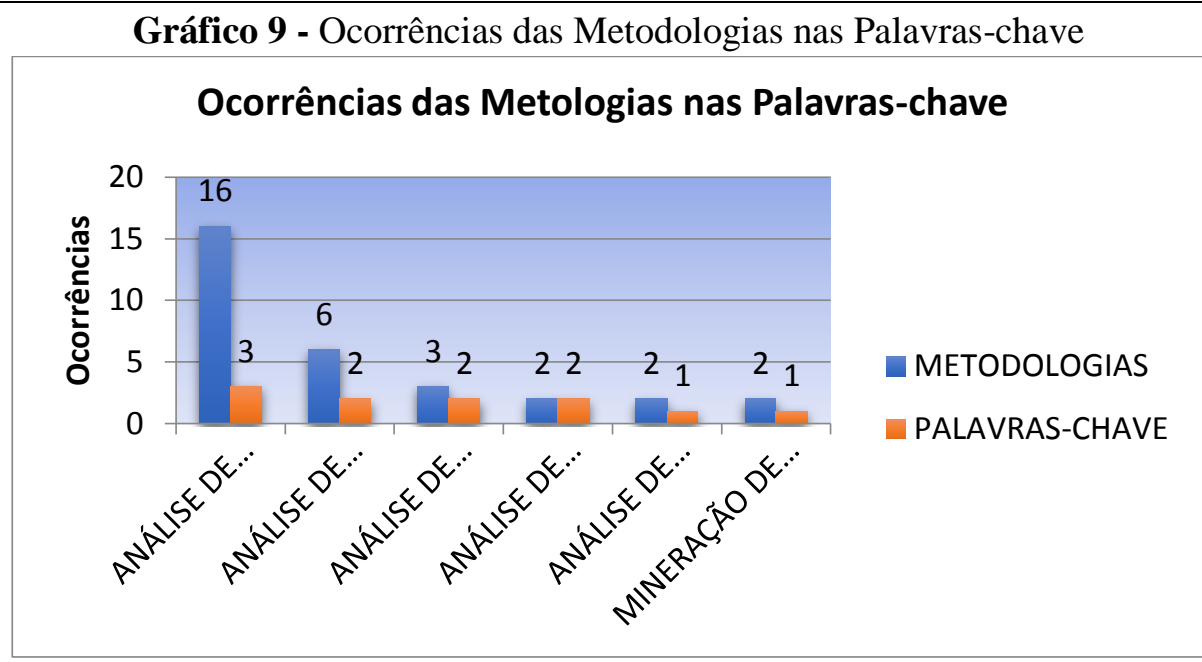

Fonte: Elaborado pelos autores

Pelas informações contidas no Gráfico 9, todas as metodologias recorrentes estão presentes nas palavras-chave, sendo que as duas metodologias mais empregadas aparecem em menor quantidade nas palavras-chave, esta informação remete-se a hipótese de que estas metodologias estão sendo aplicadas como suporte para o aprofundamento da análise, derivadas da Bibliometria.

\section{CONSIDERÇÕES FINAIS}

Ao investigar e analisar a produção na formação científica do Brasil que utilizaram a Bibliometria como referencial metodológico e suas possíveis interações com outras metodologias foram construídos diversos indicadores que podem representar o estabelecimento da Bibliometria como abordagem metodológica que está sendo associada a outras metodologias para a avaliação científica.

Os trabalhos com referencial metodológicos da Bibliometria se localizam geograficamente na região Sudeste, Sul e o Distrito Federal. No viés institucional, o indicador de produção por instituição, verificou-se que apenas 16 instituições aparecem como produtoras, em comparação com a quantidade de instituições de formação acadêmica no país e das características da Bibliometria, que favorecem as análises em todos os campos na academia, entende-se ser um número baixo. As instituições que se destacam na produção foram a USP, UFSCAR e UFRGS. Ressalta-se que essas três instituições já sediaram o principal evento da área, o EBBC.
A pesquisa revelou que o crescimento da produção é maior do que o crescimento do fomento. As ferramentas utilizadas nas Teses são diversas e se relacionam. devido a disponibilidade de ferramentas, basicamente são utilizadas ferramentas para a organização e análises de dados, como também para representação da informação. Porém a mais utilizada é o Excel, tal ferramenta é incorporada em grande parte dos sistemas operacionais disponíveis nos computadores, além de ser de fácil manuseio e uma interface quase incorporada a todos os usuários.

Muitas metodologias são utilizadas concomitantemente com a Bibliometria, porém as recorrentes são quase todas metodologias de análises, fato relevante pois indica a confrontação ou validação da análise bibliométrica com um outro referencial, endossando o caráter de interdisciplinaridade da Bibliometria. A metodologia mais utilizada foi a Análise de Conteúdo, as ocorrências foram maiores a partir do ano de 2012, remetendo ao novo olhar para os trabalhos bibliométricos.

Conclui-se que a Bibliometria é uma área de bastantes recursos e a utilização de outras metodologias conjuntamente é um fator que vem desenvolvendo e ampliando o campo. No que concerne ao desenvolvimento da pesquisa, ressalta-se que as principais dificuldades para sua elaboração recaem na coleta de dados de descritores não usualmente utilizados, exemplo nesta pesquisa são as metodologias concomitantes com a Bibliometria. Como proposição para futuras pesquisas sugere-se aumentar o escopo da pesquisa para o âmbito 
internacional para observar tendências e

lacunas do Campo.

\title{
PRESENCE OF BIBLIOMETRY AS A METHODOLOGICAL PROCESS IN INDEXED TESES IN
} IBICT (2005-2015)

\begin{abstract}
This work aims to investigate and analyze the Brazilian academic production, represented by the theses indexed in the Brazilian Digital Library of Theses and Dissertations of the Brazilian Institute of Information in Science and Technology (BDTD / IBICT), that used Bibliometry a as a methodological reference. In the theoretical sphere this research is based on studies on scientific communication, more specifically on the constructs of Bibliometry. From the methodological point of view, it is characterized by being an exploratory research in which the BDTD / IBICT was used for the construction of bibliometrics indicators. The analyzes were base don't he intrinsic procedures of science (black box), represented by methodologies. The results show that bibliometrics studies are expanding and are usually used in association with other methodologies. The promotion for these researches grows in a less marked way than the production. Bibliometrics surveys are largely exploratory, descriptive, quantitative and documentary, collection sources vary and are related, but databases are the most required. It was noticed that some graduate programs tend to use certain methodologies, suggesting specific poles of studies. The methodologies used concomitantly with Bibliometry are diverse, recurrent is content analysis. We conclude that the use of concomitant methodologies with Bibliometry is being explored more.
\end{abstract}

Keywords: Bibliometrics Analysis. Bibliometry. Indicators. Methodologies.

\section{REFERÊNCIAS}

ALVARADO, Rubén Urbizagástegui. A bibliometria no Brasil. Ciência da Informação, v. 13, n. 2, 1984. Disponível em: $<$ http://revista.ibict.br/ciinf/article/viewFile/2 00/200>. Acesso em: 30 mar. 2017.

ARAÚJO, Carlos. Alberto. Bibliometria: evolução histórica e questões atuais. Em questão, Porto Alegre, v.12, n.1, p.11-32, jan./jun.2006. Disponível em: $<$ http://www.redalyc.org/html/4656/4656459 54002/> Acesso em: 29 mai. 2017.

ARAÚJO, Ronaldo Ferreira; ALVARENGA, Lidia. A bibliometria na pesquisa científica da pós-graduação brasileira de 1987 a 2007. Encontros Bibli: revista eletrônica de biblioteconomia e ciência da informação, v. 16, n. 31, 2011. Disponível em: $<$ http://www.redalyc.org/html/147/14718352 004/>. Acesso em: 24 mar. 2017.
ARAÚJO, Ronaldo Ferreira; MURAKAMI, Tiago Rodrigo Marçal; DE VASCONCELOS ANDRADE, Robéria Lourdes. Repertório da produção periódica brasileira de Ciência da Informação: indícios embrionários. Pesquisa Brasileira em Ciência da Informação e Biblioteconomia, v. 11, n. 1, 2016. Disponível em:

<http://periodicos.ufpb.br/index.php/pbcib/art icle/viewFile/28072/15239>. Acesso em: 15 mar. 2017.

BIBLIOTECA BRASILEIRA DE TESES E DISSERTAÇÕES: Instituto Brasileiro de Informação Ciência e Tecnologia. Disponível em: <http://bdtd.ibict.br/vufind/>. Acesso em: 13 fev. 2017.

BOURDIEU, Pierre. Para uma sociologia da ciência. Lisboa: Edições 70, 2004.

BUFREM, Leilah; PRATES, Yara. O saber científico registrado $\mathrm{e}$ as práticas de mensuração da informação. Ciência da Informação, v. 34, n. 2, p. 9-25, 2005. Disponível em: 
<http://www.scielo.br/pdf/ci/v34n2/28551>. Acesso em: 25 mar. 2017.

CARRIZO SAINERO, Gloria. Hacia un concepto de bibliometría. Journal of Spanish Research on Information Science, v. 1, n. 2, p. 1-10, 2000. Disponível em: $<$ http://www.multidoc.es/SiteAssets/migracio n/Journal/pendientedemigracion.ucm.es/info/ multidoc/publicaciones/journal/pdf/bibliometr ia-esp.pdf>. Acesso em: 25 mar. 2017.

DA SILVA, Márcia Regina; HAYASHI, Carlos Roberto Massao; HAYASHI, Maria Cristina Piumbato Innocentini. Análise bibliométrica e cientométrica: desafios para especialistas que atuam no campo. InCID: Revista de Ciência da Informação e Documentação, v. 2, n. 1, p. 110-129, 2011. Disponível em: <http://www.journals.usp.br/incid/article/vie w/42337>. Acesso em 24 mar. 2017.

FARIA, L.I.L. Prospecção tecnológica em materiais: aumento da eficiência do tratamento bibliométrico: aplicação na análise de tratamentos de superfície resistentes ao desgaste. 2001. 187f. Tese (Doutorado em Ciência e Engenharia dos Materiais) Programa de Pós-Graduação em Ciência e Engenharia de Materiais, Universidade Federal de São Carlos, São Carlos.

GARRIDO FILHO, Edson Ronaldo. Redes sociais e indicadores bibliométricos: implicações sociológicas para o estudo da ciência. In: HAYASHI, Maria Cristina Piumbato Innocentini; LETA, Jaqueline. Bibliometria e cientometria: reflexões teóricas e interfaces. São Carlos: Pedro e João Editores, 2013, p. 83-108.

GIL, Antônio Carlos. Como elaborar projetos de pesquisa. São Paulo: Atlas, 2002.

GUEDES, Vânia Lisboa Silveira; BORSCHIVER, Suzana. Bibliometria: uma ferramenta estatística para a gestão da informação e do conhecimento, em sistemas de informação, de comunicação e de avaliação científica e tecnológica. In: ENCONTRO NACIONAL DE CIÊNCIA DA INFORMAÇÃO, 6.; 2005. Anais..., 2005, p. 1-18. Disponível em: <http://www.cinform-
anteriores.ufba.br/vi_anais/docs/VaniaLSGue des.pdf >. Acesso em: 11 abr. 2017.

HAYASHI, Carlos Roberto Massao. Apontamentos sobre a coleta de dados em estudos bibliométricos e cientométricos. Filosofia e Educação, v. 5, n. 2, p. 89-102, 2013. Disponível em: <http://ojs.fe.unicamp.br/ged/rfe/article/view/ 5330>. Acesso em: 11 abr. 2017.

HAYASHI, Maria Cristina Piumbato Innocentini et al. Competências informacionais para utilização da análise bibliométrica em educação e educação especial. Educação Temática Digital, v. 7, n. 1, p. 11, 2005. Disponível em: <http://search.proquest.com/openview/f1f107 52aab8b674c06e09c172e15f29/1?pqorigsite $=$ gscholar $\& \mathrm{cbl}=2029534 \mathrm{>} . \quad$ Acesso em: 24 mar. 2017.

HICKS, Diana et al. The Leiden Manifesto for research metrics. Nature, v. 520, n.7548, p. 429, 2015. Disponível em: <https://www.nature.com/polopoly_fs/1.1735 $1 ! / \mathrm{menu} / \mathrm{main} /$ topColumns/topLeftColumn/pd f/520429a.pdf?origin=ppub>. Acesso em: 30 mai. 2017.

LATOUR, Bruno. Ciência em ação: como seguir cientistas e engenheiros sociedade

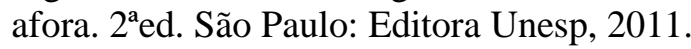

MARICATO, João de Melo; NORONHA, Daisy Pires. Indicadores bibliométricos e cientométricos em CT\&I: apontamentos históricos, metodológicos e tendências de aplicação. In: HAYASHI, Maria Cristina Piumbato Innocentini; LETA, Jaqueline, Bibliometria e cientometria: reflexões teóricas e interfaces, São Carlos: Pedro e João Editores, 2013, p. 59-82.

MUGNAINI, Rogério. 40 anos de bibliometria no Brasil: da bibliografia estatística à avaliação da produção científica nacional. In: HAYASHI, Maria Cristina Piumbato Innocentini; LETA, Jaqueline. Bibliometria e cientometria: reflexões teóricas e interfaces. São Carlos: Pedro e João Editores, 2013, p. 3758. 
SPINAK, E. Indicadores cienciométricos. Ciência da Informação, Brasília, v. 27, n. 2, p. 141-148, maio/ago. 1998.

VANTI, Nadia Aurora Peres. Da bibliometria à webometria: uma exploração conceitual dos mecanismos utilizados para medir o registro da informação e a difusão do conhecimento. Ciência da informação, v. 31, n. 2, p. 152-162, 2002. Disponível em: <http://www.scielo.br/pdf/ci/v31n2/12918>.

Acesso em: 24 mar. 2017. 